\title{
Thermoelectric Generators for Automotive Applications: Holistic Optimization and Validation by a Functional Prototype
}

\author{
MARTIN KOBER (1), ${ }^{1,2}$ TIMO KNOBELSPIES (10, ${ }^{1}$ AINA ROSSELLO, ${ }^{1}$ \\ and LARS HEBER (i) ${ }^{1}$ \\ 1.-German Aerospace Center (DLR), Institute of Vehicle Concepts, Pfaffenwaldring 38-40, \\ 70569 Stuttgart, Germany. 2.-e-mail: martin.kober@dlr.de
}

Current research has led to a significant improvement at the system level of thermoelectric generators (TEG) for automotive applications. The previously low power density could be increased considerably up to $267 \mathrm{~W} / \mathrm{kg}$ and $478 \mathrm{~W} /$ $\mathrm{dm}^{3}$. In addition, the cost-benefit ratio of the technology in the overall system of the vehicle was improved through intensive optimizations on system level. The results presented so far are based on measurement data of single thermoelectric modules (TEM) and simulation of the TEG system. In this paper the high simulative increases at the system level, achieved through a holistic optimization method, are validated by a functional prototype, completely equipped with TEM. Thereby, a functional prototype has been developed and built successfully and measured on a hot gas test bench. In the experiment all TEM show a stable power output and the highest gravimetric power density of automotive TEG systems known to the authors could be measured. Further tests will be performed with the functional prototype as described in the outlook. In addition to the successful tests, the simulation is validated with the detailed measurement data. After adapting the measurement method of the TEM for providing more accurate TEM measurement data as input for the simulation, a suitable match could be achieved between the TEG simulation and the experiment. In the measurement points performed so far, the accuracy of the simulated temperatures reaches more than $95 \%$. The accuracy of the simulated output power is more than $97 \%$.

Key words: Thermoelectric generator, automotive application, waste heat recovery, conventional vehicles,

holistic overall system development, cost-benefit ratio

CO Coolant

List of Symbols

$\mathrm{CO}_{2} \quad$ Carbon dioxide

COHX Coolant heat exchanger

DLR Deutsches Zentrum für Luft- und

Raumfahrt/German Aerospace Center $\begin{array}{ll}\text { DSG } & \text { Dual-clutch gearbox } \\ \text { HG } & \text { Hot gas } \\ \text { HGHX } & \text { Hot gas heat exchanger } \\ \text { ICE } & \text { Internal combustion engine } \\ \text { MP } & \text { Measuring point } \\ \text { OP } & \text { Operating point } \\ \text { TEG } & \text { Thermoelectric generator } \\ \text { TEM } & \text { Thermoelectric module } \\ \text { TSI } & \text { Turbocharged stratified injection } \\ \text { WLTC } & \text { Worldwide harmonized light duty driving } \\ & \text { test cycle } \\ W_{\mathrm{p}} & \text { Peak power }\end{array}$ 


\section{INTRODUCTION}

In automotive development, one of the major challenges is to achieve the required reductions in $\mathrm{CO}_{2}$ emissions. Various scenario analyses predict that even in electric vehicle friendly studies, the proportion of vehicles with combustion engines is dominant in future vehicle sales. For example, the prediction of the vehicle sales for 2030 in the study of Ref. 1 and in the meta-study of Ref. 2 has a share of more than $80 \%$ of vehicles with internal combustion engines, including a large share of hybrid vehicles. A look at the overall $\mathrm{CO}_{2}$ balance of purely electric vehicles with a large battery range shows that in many areas vehicles powered by internal combustion engines currently has a better $\mathrm{CO}_{2}$ balance. ${ }^{3-6}$ With the continued use of internal combustion engines, to whatever extent, it is necessary to investigate all potential technologies for efficiency improvement. Regardless of whether a conventional or hybrid vehicle concept is used, approximately two thirds of the fuels chemical energy dissipates as waste heat. In particular, the part of the exhaust gas offers the highest potential for waste heat recovery due to its high temperature level. The technology of thermoelectric generators (TEG) is very promising for waste heat recovery and under investigation for several years, e.g. at the DLR-Institute of Vehicle Concepts in Stuttgart since $2005 .^{7-11}$

In the latest work, a high increase in gravimetric and volumetric power density could be achieved. The cost-benefit ratio could also be significantly improved by using a modern design method. For example, the highest power density for automotive TEG systems was presented in Ref. 12 with 267 W/ kg. Furthermore, in Ref. 12 a cost-benefit ratio of less than $81 € /(\mathrm{g} / \mathrm{km})$ was achieved using the holistic design method. In this paper, a functional prototype based on a concrete TEG optimization is used to demonstrate that the high increases can also be proven experimentally.

\section{METHODOLOGY FOR A HOLISTIC TEG OPTIMIZATION}

In order to give an overview of the methodological procedure, the optimization method is presented in this chapter. This method was used to design the TEG system, which is built up as a functional prototype. Below, an overview of the used holistic TEG optimization method is shown, and the method is described in detail in Ref. 12. A comparison between the optimization for a conventional vehicle and a hybrid vehicle is also shown in Ref. 12 . In, Ref. 13 a comparison of the potentials for waste heat recovery in conventional and hybrid vehicles is shown. Figure 1 shows the holistic method for the optimization of TEG system. The two primary objectives presented there are aimed to maximize the $\mathrm{CO}_{2}$ reduction of the overall system within the driving cycle WLTC $(\mathrm{g} / \mathrm{km})$ and to minimize the TEG system costs $(€)$.

The simulation is based on a highly integrated TEG design Thereby multiple functional integrations were performed according to a methodical procedure. This resulted in reduced number of components as well as lower weight and costs.

In order to include the holistic aspect, all interactions between vehicle and TEG system are dynamically calculated and included in the optimization.

The relevant interactions between the vehicle and the TEG system are shown in Fig. 2. The interactions within the cycle are implemented in the dynamic simulation. Thus, an automated parameter

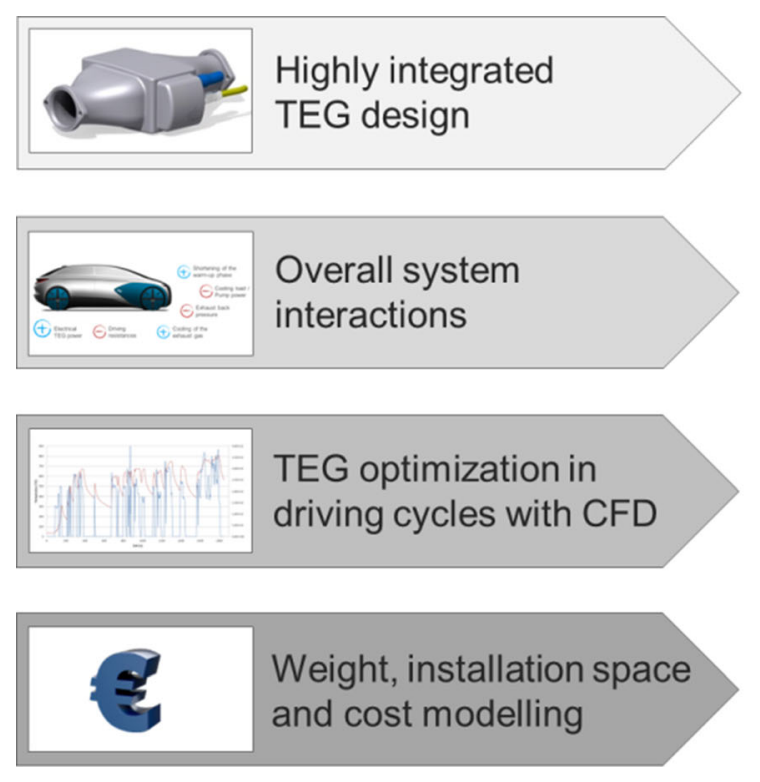

\section{Multi-objective optimization}

Max. efficiency of the overall system

Min. system costs

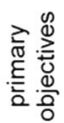

Min. exhaust back pressure

Max. power density

Homogeneous temperature field
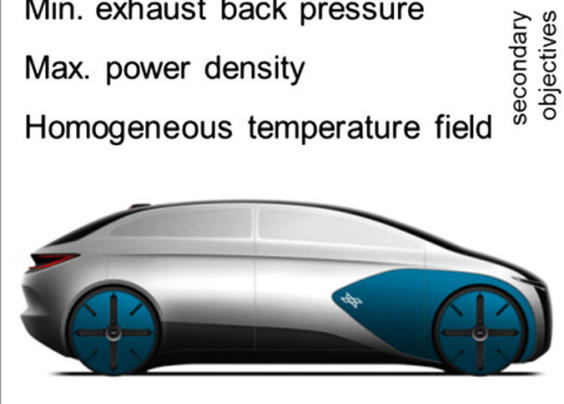

Fig. 1. Holistic method for TEG optimization. ${ }^{12}$ 
variation can be carried out during the optimization and the simulation returns the effectively achievable $\mathrm{CO}_{2}$ reduction within the WLTC.

The cost-benefit ratio was defined as the global objective. This is the ratio between the effective reached $\mathrm{CO}_{2}$ reductions per $\mathrm{km}$ in the WLTC and the costs. In the European Union there is a penalty for exceeding a defined fleet consumption. A TEG system with a cost-benefit ratio of less than $95 € /(\mathrm{g} /$ $\mathrm{km}$ ) would be more economical than the imminent penalty payments.

A direct cost-benefit optimization requires an automated calculation of the entire system costs. Therefore, a generic tool was developed which is determining the weight, installation space and the system costs of each TEG design.

In order to achieve a balanced TEG design, a further eight secondary objectives were defined to evaluate the behavior outside of the WLTC. These secondary objectives include properties such as peak performance, thermal stability and exhaust back pressure.

\section{RESULTS OF THE HOLISTIC OPTIMIZATION}

This paper presents a functional prototype of a TEG for a conventional compact class vehicle.

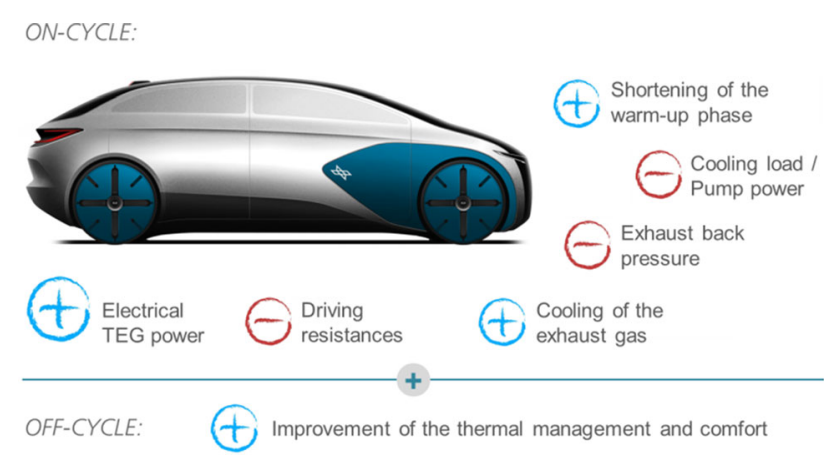

Fig. 2. Overall system interactions of the TEG system with the vehicle. $^{12}$
A Volkswagen Golf with a turbocharged engine and $1.2 \mathrm{~L}$ displacement was selected as the boundary condition for the optimization. Table I shows the main characteristics of the reference vehicle.

The input for the simulation is data from tests on the roller dynamometer. For this purpose, the measured data sets of the WLTC for temperatures and mass flows of the exhaust gas and coolant are used. The measured data of the combustion engine regarding speed, torque and temperatures are also used.

In the methodical procedure presented in the previous chapter, an automatized optimization of the entire TEG system is performed, and thereby all relevant parameters are varied. The two primary objectives and the eight secondary objectives are optimized. The result is a ten-dimensional Pareto set.

In order to visualize the result, the two primary objectives are plotted as a Pareto front in Fig. 3. The ordinate shows the $\mathrm{CO}_{2}$ reduction effectively achieved in the overall system within the WLTC. The abscissa specifies the corresponding costs for the entire TEG system. Each dot in the diagram represents the result for one set of input parameters. With the optimization algorithm, the optimization is continued until there is no significant change in the 10 objectives.

Further, a resulting design can be selected from the result set. To visualize the selection a simplification to the two primary objectives is charted in Fig. 4. However, the real selection is based on a detailed method ${ }^{12}$ in which the eight secondary objectives are also taken into account. Thereby, a resulting design is selected from the ten-dimensional Pareto set with regard to a weighting of the different objectives.

The visualization in Fig. 5 shows that a $\mathrm{CO}_{2}$ reduction of $2.2 \%$ is reachable within the WLTC. If the best cost-benefit ratio is selected, a $\mathrm{CO}_{2}$ reduction of $1.9 \%$ is achieved.

The resulting design selected from the ten-dimensional Pareto set leads to a $\mathrm{CO}_{2}$ reduction in the reference vehicle of $2.5 \mathrm{~g} / \mathrm{km}$. This design achieves

Table I. Main characteristics of the reference vehicle

\begin{tabular}{|c|c|c|c|c|c|c|}
\hline & $\begin{array}{c}\text { Vehicle } \\
\text { type } \\
(-)\end{array}$ & $\begin{array}{l}\text { Battery } \\
\text { capacity } \\
(\mathbf{k W h})\end{array}$ & $\begin{array}{c}\text { ICE } \\
(-)\end{array}$ & $\begin{array}{l}\text { Type of } \\
\text { engine } \\
(-)\end{array}$ & $\begin{array}{c}\text { Displacement } \\
\left(\mathbf{d m}^{3}\right)\end{array}$ & $\begin{array}{c}\text { Max. } \\
\text { performance } \\
(\mathbf{k W})\end{array}$ \\
\hline Volkswagen Golf VII & $\begin{array}{l}\text { Operating } \\
\text { strategy } \\
(-)\end{array}$ & $\begin{array}{c}\text { Transmission } \\
(-)\end{array}$ & $\begin{array}{l}\text { Weight of } \\
\text { vehicle } \\
\text { (kg) }\end{array}$ & $\begin{array}{l}\text { Year of } \\
\text { launch } \\
\quad(-)\end{array}$ & $\begin{array}{c}\text { Fuel consumption } \\
(\text { measured }) \\
(1 / 100 \mathbf{~ k m})\end{array}$ & $\begin{array}{c}\mathrm{CO}_{2} \text { emissions } \\
\text { (calculated) } \\
(\mathbf{g} / \mathbf{k m})\end{array}$ \\
\hline Volkswagen Golf VII & Start-stop & Autom. (DSG) & 1300 & 2012 & 5.63 & 131.2 \\
\hline
\end{tabular}



by a Functional Prototype

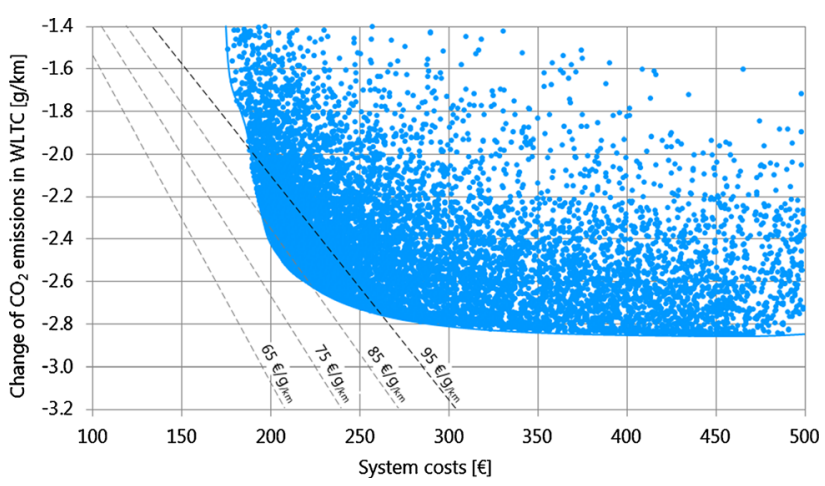

Fig. 3. Result of the TEG optimization-Pareto front of the two primary objectives.

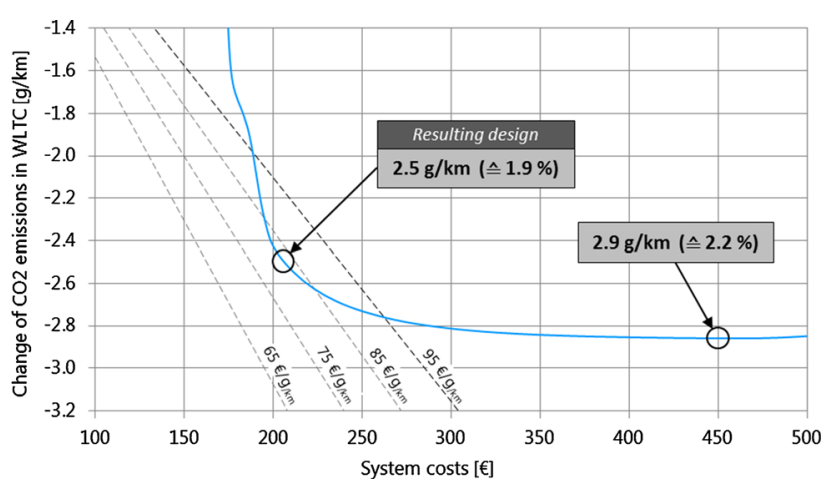

Fig. 4. Pareto front of the two primary objectives.

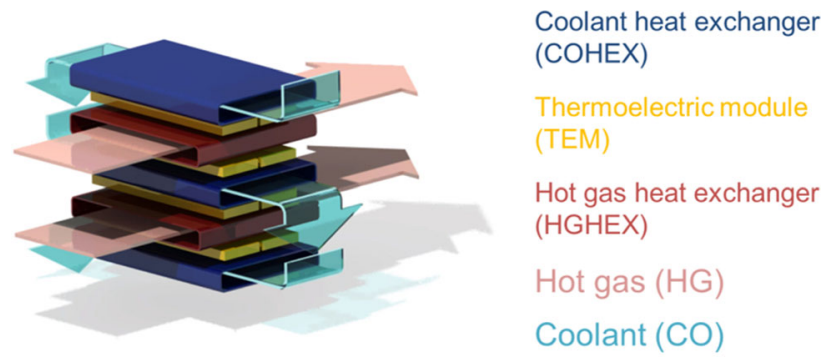

Fig. 5. Cross-flow heat exchanger system. ${ }^{12}$

an optimum between system costs and benefits in the WLTC. In addition, it also shows good values for the secondary objectives according to their importance. Calculated with the basic emissions according to Table $\mathrm{I}$ a $\mathrm{CO}_{2}$ reduction of $1.9 \%$ is reached. Thereby, the overall system interactions, shown in Fig. 2, are taken into account. In general, $\mathrm{CO}_{2}$ emissions are equivalent to the fuel consumption due to the chemical composition of the fuel. For this reason, the fuel reduction achieved in the overall system within the WLTC is also $1.9 \%$.

The results are based on the measured input data of the reference vehicle in the WLTC. The measured time-dependent profiles for temperatures and mass flows of the exhaust gas and coolant are used. In a further step, the maximum performance of the costbenefit optimized TEG is analyzed. For this purpose, the load point of the vehicle is increased in the simulation until the maximum local TEM hot side temperature of $600^{\circ} \mathrm{C}$ is reached. A coolant temperature of $20^{\circ} \mathrm{C}$ is used only for the examination of the maximum performance. This corresponds to the temperature in the cooling system during a drive at low ambient temperatures. However, the simulation of the WLTC described above is computed with the measured time-dependent temperature profiles of the cycle as input, which are measured at an ambient temperature of $20^{\circ} \mathrm{C}$. As a result from the analysis of the rated power, a maximum peak power of $726 \mathrm{~W}$ is reached. The resulting design presented above is also presented in Ref. 7.

However, the functional prototype described in the following chapter is based on an earlier development. This development represents a preliminary stage of the optimization, which is executed with the same holistic method, but in an earlier version. The same reference vehicle is used for both versions of the design. The preliminary design, which is built as functional prototype, is presented in Ref. 8. It has a rated power of $526 \mathrm{~W}$.

The increase of the values between two optimization stages shows that intensive optimization can lead to significant improvements. These have not yet been completely exploited, and further increases are expected for the future. The increases achieved within the context of this work are also shown in Fig. 12 on the basis of the gravimetric power density and in Ref. 12 on the basis of the volumetric power density.

\section{VALIDATION BY A FUNCTIONAL PROTOTYPE}

Based on the shown results, a functional prototype is built in order to confirm these data and to validate the CFD simulation. The geometry of the hot gas heat exchangers is given by the previously explained optimization. The structural design of the prototype is specified by the highly integrated TEG design. The basic structure of the highly integrated TEG design is shown in Fig. 5. It is based on a crossflow heat exchanger system.

Figure 6 shows the housing and the principle construction of the highly integrated TEG design.

Many components of the highly integrated TEG design have several functions. As an example the housing fulfills multiple functions, such as the provision of the inert gas atmosphere, the guidance of the coolant and the integration of the power electronics. This leads to fewer required components and results in less weight and lower costs which has a direct impact on the power density and on the cost-benefit ratio.

The inert gas atmosphere is used to protect the thermoelectric half-Heusler modules from degeneration. However, this also means that the measurement technology needs a gas tight bushing system. 


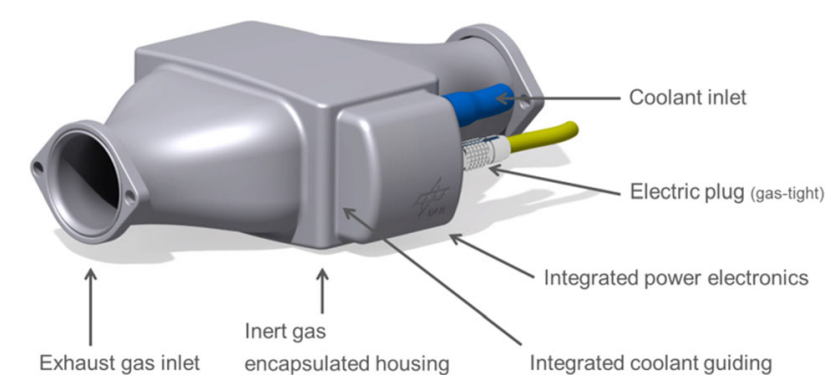

Fig. 6. Highly integrated TEG design. ${ }^{12}$

Therefore, an additional measurement box is needed as shown in Fig. 9. In order to thermally measure the prototype, 58 type $\mathrm{K}$ thermocouples are integrated into the prototype. Of course, these are only intended for the measurements and not required for the operation of the TEG system itself.

The majority of thermocouples are used to measure the surface temperature of the heat exchangers. These temperatures are analogous to the TEM hot and cold side temperatures on the outside of the thermal interface. Therefore, the heat exchangers are prepared with slots in which the thermocouples are inserted. In this way, the surface temperatures of the heat exchangers are measured directly without influencing the temperature profile by integrating the thermocouples. The schematic Fig. 7 shows the hot gas heat exchanger with the measuring points in flow direction. $\mathrm{P} 2^{*}$ and $\mathrm{P} 5^{*}$ are mirrored points to check the symmetry. In the evaluation they are averaged together with the corresponding points on the opposite side (P2 and P5). In addition, the integration of the thermocouples in the prototype can be seen in Fig. 7 .

Figure 8 shows the functional prototype which includes the TEG-core, the power electronics and the additional measurement, the measurement box and the gas-tight cable bushing. The power electronics contains four independent MPPT with one DC/DC converter each, to optimally convert the electrical energy.

Figure 9 shows the functional prototype where the additional measurement is highlighted. The not highlighted components also correspond to the volume that is necessary for the installation of the TEG into a vehicle.

Because of cooperation between Yamaha and the DLR Institute of Vehicle Concepts, ${ }^{14}$ it is possible to use highly efficient half-Heusler modules for the optimization. With a Yamaha, there is a measured efficiency of up to $7 \%$ at a hot side temperature of $550^{\circ} \mathrm{C}$ and a cold side temperature of $80^{\circ} \mathrm{C}$. The used optimization also improves the thermoelectric modules, so that Yamaha developed modules especially for this prototype according to the DLR specifications. The modules used for the prototype are shown in Fig. 10.

The functional prototype has been tested on the test bench of the DLR Institute for Vehicle
Concepts. This test bench replicates the three relevant subsystems of the vehicle. A hot gas generator reproduces the exhaust system of the vehicle. It generates temperatures up to $1200^{\circ} \mathrm{C}$ and mass flows up to $1000 \mathrm{~kg} / \mathrm{h}$ dynamically. An experimental cooling system has been developed and integrated into the test bench to reproduce the vehicle's cooling system. Thus, a precise control of the coolant temperature and volume flow can be performed. In order to model the electrical system of the vehicle, several electrical loads are available.

Ten operating points $(\mathrm{OP})$ with different hot gas temperatures and mass flows has been measured. The mass flow of the hot gas was varied between $36 \mathrm{~kg} / \mathrm{h}$ and $143 \mathrm{~kg} / \mathrm{h}$, and the temperature between $279^{\circ} \mathrm{C}$ and $672^{\circ} \mathrm{C}$. The peak power of the functional prototype has not yet been measured in order to avoid thermally critical ranges for the time being.

The different operating points are also simulated with the CFD simulation which is included in the holistic overall system optimization. Thus, the simulation is directly comparable with the measured values and can be validated.

\section{RESULTS OF THE FUNCTIONAL PROTOTYPE}

In the experiments carried out so far, the entire structure and all thermoelectric modules have survived. The measurement results also show that the function of the new heat exchangers is given and the desired temperatures could be achieved at the TEM. In comparison between experiment and simulation, the average hot side temperature has a deviation of $6.3 \%$ and the cold side temperature deviates by $3.4 \%$. This ensures thermal consistency. Further, however, the comparison shows a significant deviation in the electrical output power with a deviation of up to $30 \%$.

Based on these data, a further study was carried out and the deviation was concluded with the assumption that the TEM efficiency used in the simulation did not match the functional model.

The simulation, as already described, was based on measurement data from a TEM test bench of Yamaha. In this context the measuring technique of the TEM was examined and improved further by Yamaha. As result the measurement data of the modules could be re-evaluated. Then again the new TEM data for efficiency and thermal resistance were integrated into the simulation. The results of this simulation is described below and based on these new module data without a modification of the TEM itself. The module design is still the original from 2017.

Table II shows an exemplary selection of operating points with the simulated and measured average hot and cold side temperatures as well as the electrical power. The average value is calculated over all measuring points for the hot, respectively, cold side. The electrical power is measured without 

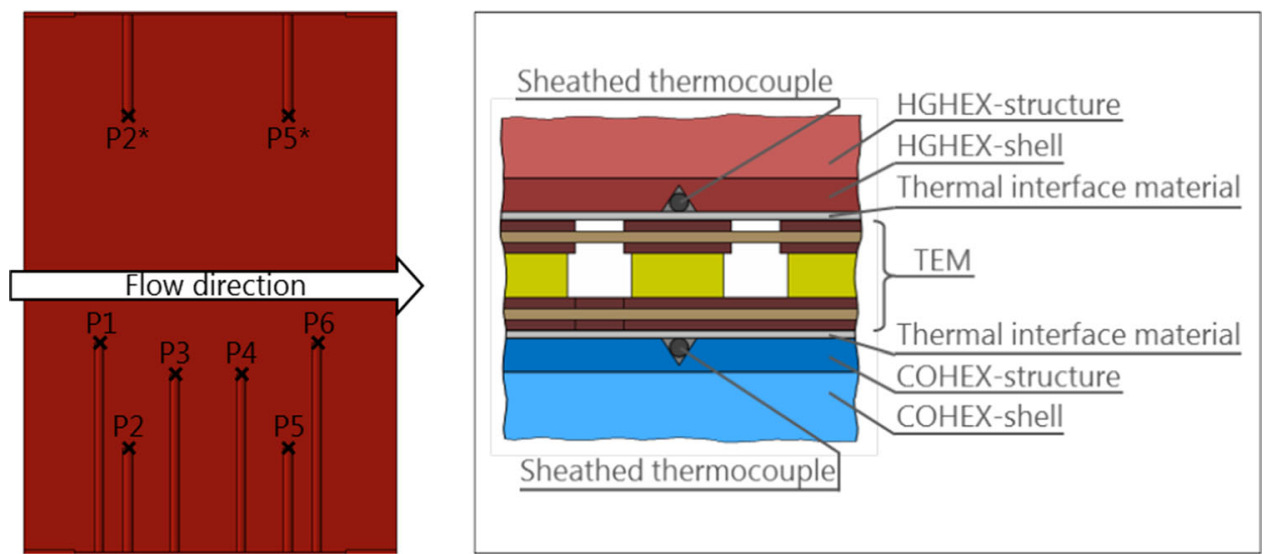

Fig. 7. Heat exchanger with the used measuring points in flow direction and integration concept of the thermocouples to measure the surface temperatures of the heat exchangers.

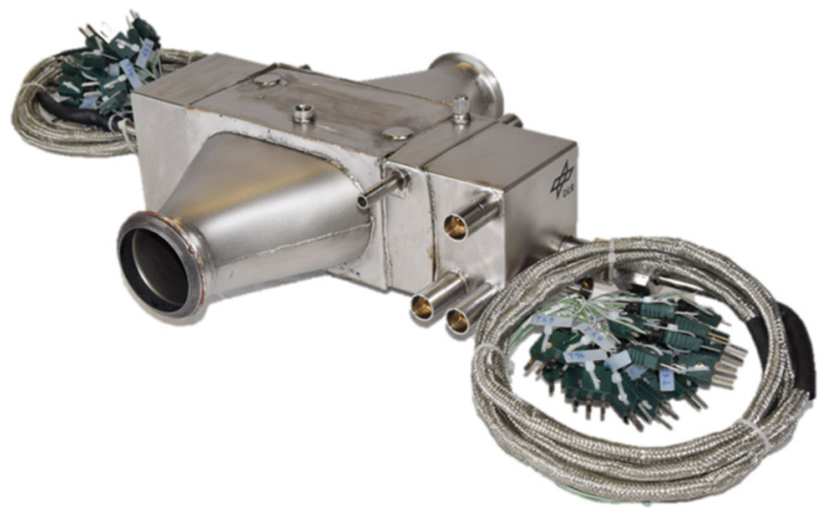

Fig. 8. Functional TEG prototype.

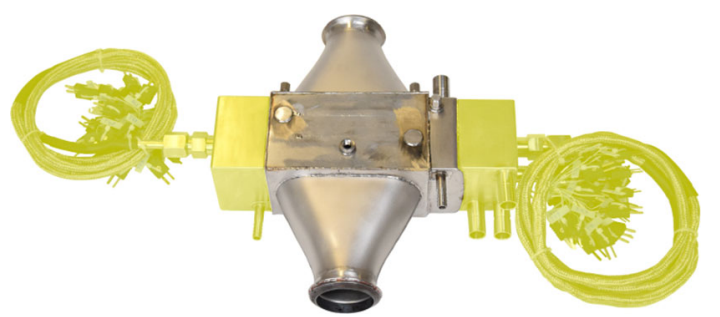

Fig. 9. Functional TEG prototype with additional measurement highlighted.

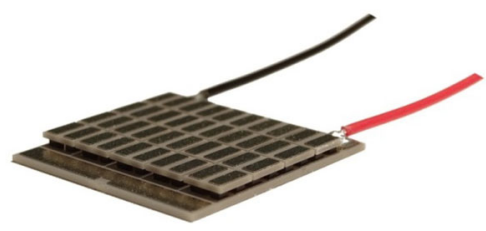

Fig. 10. Half-Heusler thermoelectric module. Reprinted from Ref. 14 under CC License BY 3.0. using the power electronics of the TEG; therefore, a more precise power potentiostat is used.

The comparison of the values in Table II shows that the measured values are achieved in the simulation with an accuracy of $95 \%$ related to the temperature and an accuracy of $97 \%$ for the electrical power. The average deviation over all ten operating points is $1.5 \%$ for the hot side, $3.5 \%$ for the cold side and $4.0 \%$ for the electrical output power.

To validate the CFD simulation, the temperature profile in flow direction is used. For this purpose, the measuring points are averaged in accordance with their position, as shown in Fig. 7. These averaged measuring points are compared with the temperature profile of the CFD simulation. Figure 11 shows an exemplary profile for the operating point 5 .

The solid lines show the simulated temperatures, the dots show the measuring points for the hot side and the cold side. For the hot side, the quantitative temperature profile fits very well. The qualitative match between simulation and measurement is shown above in Table II. The measuring points P2 and P5 deviate slightly from the simulated temperature profile on the hot side. Figure 7 shows that the measuring points P2 and P5 are located further away from the center of the heat exchanger. The CFD simulation calculates a flow channel exactly in the middle of the heat exchanger. Therefore, the deviation of the measuring points MP2 and MP5 is also plausible.

The simulation of the cold side shows a slightly lower accuracy. The reason for this is seen in a simplified modeling of the coolant heat exchanger in the simulation model. However, as can be seen in Table II, the influence on the simulated electrical output power is marginal.

Based on these results, the simulation model is classified as validated. The simulated average hot and cold side temperatures matches at different 
Table II. Exemplary operating points (OP) from the measurements

\begin{tabular}{|c|c|c|c|c|c|c|}
\hline & \multicolumn{2}{|c|}{ Hot side temperature average $\left({ }^{\circ} \mathrm{C}\right)$} & \multicolumn{2}{|c|}{ Cold side temperature average $\left({ }^{\circ} \mathrm{C}\right)$} & \multicolumn{2}{|c|}{ Electrical power $(W)$} \\
\hline & Measured & Simulated & Measured & Simulated & Measured & Simulated \\
\hline OP 05 & 247.95 & 247.53 & 44.82 & 42.59 & 67.31 & 69.5 \\
\hline OP 06 & 252.46 & 259.5 & 42.81 & 44.24 & 74.43 & 76.66 \\
\hline OP 07 & 308.8 & 311.15 & 50.45 & 51.62 & 113.18 & 111.28 \\
\hline OP 08 & 299.98 & 306.09 & 49.63 & 50.70 & 104.9 & 107.74 \\
\hline OP 10 & 449.04 & 445.59 & 66.8 & 70.55 & 236.47 & 231.53 \\
\hline
\end{tabular}

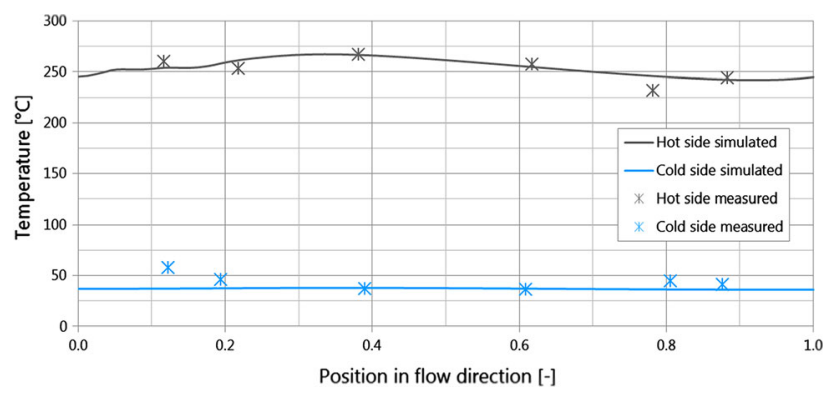

Fig. 11. Temperature profile for the operating point 5.

operating points with the measurement, as well as the electrical output power. The simulated temperature profile in flow direction also coincides with the measured values.

By adapting and optimizing the geometry of the modules and by using improved half-Heusler material, ${ }^{15}$ it also appears possible to produce modules with an efficiency of over $7 \%$. Thus, the first simulation results of $526 \mathrm{~W}^{8}$ for the tested design and $726 \mathrm{~W}^{7,12}$ for the current development stage are considered to be achievable.

\section{CONCLUSIONS AND OUTLOOK}

The holistic TEG optimization is presented using the example of a conventional vehicle. A functional prototype is built and measured. With this data the CFD simulation is validated. It is shown that the accuracy of the simulation is more than $95 \%$ for the temperatures. In addition, it is shown that the highly integrated TEG design can be successfully implemented. This design could be built with all planned conventional manufacturing methods. All thermoelectric modules within the prototype endure the measurements. The modules have the same internal resistance after assembly and measurement. Thus, after the measurement campaign, all thermoelectric modules are still functional. This confirms that the thermomechanical stresses are within the limits. The protective inert gas atmosphere is successfully created and maintained during the measurements. The power electronics are cooled during the entire measurement. This shows that the integration of the power electronics into the design can be realized.

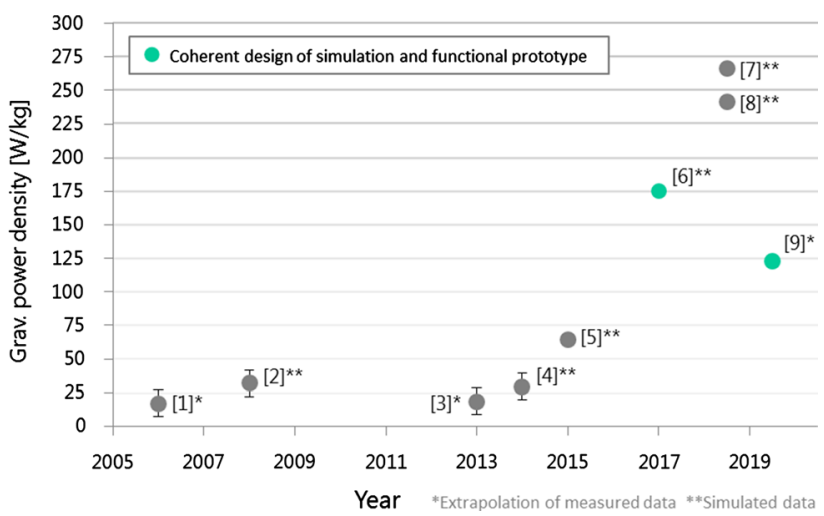

Fig. 12. Development of the gravimetric and volumetric power density for TEG over the years. (References: [1], ${ }^{16,17}$ [2], ${ }^{17}$ [3], ${ }^{18}$ $[4],{ }^{19}[5],{ }^{20}$ [6] Simulation data that corresponds to the functional prototype of this work, ${ }^{8}[7],{ }^{12}[8],{ }^{12}$ [9] Measurement results of the functional prototype in this work).

The measurement of the peak power is still pending. Nevertheless, the existing measurement data show that this TEG-prototype already has the highest measured power density known by the authors for a TEG system designed for vehicle application.

Figure 12 shows that the gravimetric power density in various TEG projects remained in a similar range over years. In 2015 the highly integrated design and holistic overall system optimization similar to this work in a previous version is realized for the first time. ${ }^{20}$ The presented functional prototype is based on simulated data presented in Ref. 8 . With further optimization the power density could be increased to $242 \mathrm{~W} / \mathrm{kg}$. ${ }^{12}$ The functional prototype of this work is intended to validate the simulative achieved power density. Up to the time of publication only partial load points have been measured. After a modification of the hot gas test bench it is planned to realize further measurements. Thereby, also an evaluation in a long-term test is planned.

In order to determine the power density achieved with this functional prototype, a measurement of the maximum peak power is required. As described, this will be done in the future. To the current state the achieved power density was, therefore, extrapolated on the basis of the measured partial load points. As shown in Fig. 12, about $70 \%$ of the 
simulated power density could be achieved. By the changes in the measuring technique of the TEM, which provided the input for the simulation, this deviation could be methodically detected. Taking these changes into account, the accuracy of the simulated output power is more than $97 \%$ compared to the functional prototype. As a result, the simulation method could be validated through the functional prototype. Moreover, it appears possible to achieve the original efficiency of the TEM with different changes in material and design. Therefore, the values achieved in the simulation will be classified as realizable.

\section{ACKNOWLEDGMENTS}

Open Access funding provided by Projekt DEAL.

\section{OPEN ACCESS}

This article is licensed under a Creative Commons Attribution 4.0 International License, which permits use, sharing, adaptation, distribution and reproduction in any medium or format, as long as you give appropriate credit to the original author(s) and the source, provide a link to the Creative Commons licence, and indicate if changes were made. The images or other third party material in this article are included in the article's Creative Commons licence, unless indicated otherwise in a credit line to the material. If material is not included in the article's Creative Commons licence and your intended use is not permitted by statutory regulation or exceeds the permitted use, you will need to obtain permission directly from the copyright holder. To view a copy of this licence, visit http://creativecom mons.org/licenses/by/4.0/.

\section{REFERENCES}

1. U. Kugler, J. Brokate, C. Schimeczek, and S. Schmid, Powertrain scenarios for cars in european markets to the year 2040 (elib DLR, 2017). https://elib.dlr.de/114744/. Accessed 10 Jan 2019

2. G. Berckmans, M. Messagie, J. Smekens, N. Omar, L. Vanhaverbeke, and J.V. Mierlo, Energies 10, 1314 (2017). h ttps://doi.org/10.3390/en10091314.

3. U. Kugler, and H. Dittus, Elektrisch Mobil in der Erzdiözese Freiburg (DLR, 2017), https://www.dlr.de/dlr/Portaldata/1/ Resources/documents/2018/DLR_2018_Stuttgart_Studie-ele ktrischmobil.pdf. Accessed 10 Jan 2019.

4. Bundesministerium für Umwelt, Wie klimafreundlich sind Elektroautos? (BMU, 2019). https://www.bmu.de/fileadmin/ Daten_BMU/Download_PDF/Verkehr/emob_klimabilanz_20 17_bf.pdf. Accessed 10 Jan 2019.

5. Agora Verkehrswende, Klimabilanz von Elektroautos (AGORA Verkehrswende, 2018). https://www.agora-verkeh rswende.de/fileadmin/Projekte/2018/Klimabilanz_von_Elekt roautos/Agora-Verkehrswende_22_Klimabilanz-von-Elektro autos_WEB.pdf. Accessed 10 Jan 2019.

6. C. Buchal, H.-D. Karl, and H.-W. Sinn, Kohlemotoren, Windmotoren und Dieselmotoren: Was zeigt die CO2-Bilanz? (ifo Institut, 2019), https://www.ifo.de/DocDL/sd-2019-08-si nn-karl-buchal-motoren-2019-04-25.pdf. Accessed 25 Apr 2019 .

7. M. Kober, Holistic Optimization of Thermoelectric Generators for Automotive Applications: Reaching a Cost Benefit Ratio of $81 € /(\mathrm{g} / \mathrm{km})$ (elib DLR, 2018). https://elib.dlr.de/ 125922/. Accessed 10 Jan 2019.

8. M. Kober, Thermoelectric Generators for Automotive Applications: A New Approach to Reach the Cost-Benefit Target (elib DLR, 2017). https://elib.dlr.de/115947/. Accessed 10 Jan 2019

9. M. Kober and H. Friedrich, Thermoelectric Generators (TEG) with high power density for application in hybrid cars (elib DLR, 2016). https://elib.dlr.de/107902/. Accessed 10 Jan 2019.

10. C. Häfele, Entwicklung fahrzeuggerechter Thermoelektrischer Generatoren zur Wandlung von Abgaswärme in Nutzenergie, Forschungsbericht 2016-08 (Köln: Deutsches Zentrum für Luft- und Raumfahrt, 2016).

11. M. Kober, C. Häfele, and H. Friedrich, Methodical Concept Development of Automotive Thermoelectric Generators (elib DLR, 2016). https://elib.dlr.de/79163/. Accessed 10 Jan 2019.

12. M. Kober, J. Electron. Mater. (2020). https://doi.org/10.1007/ s11664-020-07966-6.

13. M. Kober, J. Electron. Mater. (2020)https://doi.org/10.1007/ s11664-020-07991-5.

14. Deutsches Zentrum fuer Luft- und Raumfahrt e.V., DLR is cooperating with Yamaha Corporation to develop thermoelectric vehicle systems (Homepage DLR, 2019). https://ww w.dlr.de/content/en/articles/news/2017/20170201_dlr-is-coop erating-with-yamaha-corporation-to-develop-thermoelectri c-vehicle-systems_20587.html. Accessed 01. Nov 2019.

15. M. Müller, VACOTHERM - Thermoelektrische Werkstoffe (Homepage Vacuumschmelze, 2019). https://vacuumschmel ze.de/Produkte/Einzigartige-Technologien/Thermoelektrisc he-Werkstoffe-VACOTHERM. Accessed 10 Jan 2019.

16. H. Friedrich, M. Schier, C. Häfele, and T. Weiler, Strom aus Abgasen - Fahrzeuggerechte Entwicklung Thermoelektrischer Generatoren (elib DLR, 2010). https://elib.dlr.de/74 793/. Accessed 10 Jan 2019.

17. B. Mazar, Gesamtsystemoptimierung eines thermoelektrischen Generators für eine Fahrzeuggruppe (München: Verlag Dr. Hut GmbH, 2010).

18. U. Rusche, D. Rabeiga, M. Padberg, and T. Bukes, Indus trialisierungskonzept für hochtemperaturtaugliche thermoelektrische Generatoren zur Abgaswörmenutzung in Automobilen auf Basis neuartiger Materialien (Leibniz-Informationszentrum Technik und Naturwissenschaften und Universitätsbibliothek, 2014). http://edok01.tib.uni-hannove r.de/edoks/e01fb15/835362795.pdf. Accessed 10 Jan 2019.

19. D. Jänsch, J. Topalova-Gura, and M. Aengenheister, TEG2020 - Entwicklung modularer leistungsstarker und flexibel einsetzbarer thermoelektrischer Generatoren zur thermischen Rekuperation in Verbrennungskraftmaschinen und -anlagen (Leibniz-Informationszentrum Technik und Naturwissenschaften und Universitätsbibliothek, 2015). h ttp://edok01.tib.uni-hannover.de/edoks/e01fb16/856426342. pdf. Accessed 10 Jan 2019.

20. M. Kober, L. Heber, J. Heuer, F. Rinderknecht, J. König, and H. Friedrich, RExTEG - Neuartiger Thermoelektrischer Generator zur Steigerung der Effizienz von Hybrid- und Range Extender Fahrzeugen (elib DLR, 2015). https://elib.d lr.de/98080/. Accessed 10 Jan 2019

Publisher's Note Springer Nature remains neutral with regard to jurisdictional claims in published maps and institutional affiliations. 